\title{
ALCOOLISMO FEMININO: SUBSÍDIOS PARA A PRÁTICA PROFISSIONAL DA ENFERMAGEM.
}

\author{
Feminine alcoholism: Subsidies for the Professional Practice \\ of the Nursing. \\ El alcoholismo femenino: Los subsidios para la Práctica \\ Profesional de la Enfermería.
}

Jurema Gouvêa de Souza ${ }^{1}$

José Mauro Braz de Lima²

Rosângela da Silva Santos ${ }^{3}$

\section{RESUMO}

Trata-se de pesquisa qualitativa. Utilizou o Método de História de Vida e teve por objetivos analisar as conseqüências do uso abusivo de bebida alcoólica e discutir a assistência de saúde de que se precisa e dispõe. As 30 depoentes estavam na faixa etária de 20 a 60 anos. 0 estudo evidenciou que as mulheres fazem uso abusivo de bebida alcoólica para esquecer ou amenizar as conseqüências de dificuldades financeiras; divergências na relação conjugal; violência física; exaustiva jornada de trabalho. As conseqüências do consumo abusivo são problemas de saúde; privações; maus tratos; dificuldades de relacionamento familiar e conjugal; problemas físicos; psicológicos; tentativa de suicídio; abandono de filhos e marido. Conclusões: as mulheres não referiram oferta de serviços de saúde. Toda e qualquer iniciativa governamental deve ser inclusiva, valorizando e incentivando a participação da comunidade e de Organizações da Sociedade Civil, congregando ações e saberes das áreas tecnológicas, humanas e de saúde.

Palavras-chave: Enfermagem. Mulher. Alcoolismo.

\begin{abstract}
The present is a qualitative research. It has taken the Life History Method and aimed to assess the consequences of alcohol abuse and discuss necessary and accessible health care. The 30 deponents were in a band age of 20 to 60 years old. The study showed that the women abuse alcohol in order to forget or minimize the consequences of financial difficulties; differences in marital relationships; physical violence and; exhausting work journeys. Outcomes of alcohol abuse are health problems; deprivation; maltreatment; difficulties in family life and in marital relations; physical and psychological problems; suicide attempts and; abandoning of children and husband. The study followed to conclude that the women have not mentioned any health care offer, and affirm that any governmental initiative has to be inclusive, valuing and encouraging community and Civil Society Organizations engagement, so as to congregate technological, human and medical actions and know-how.
\end{abstract}

\section{Resumen}

Se trata de una investigación cualitativa. El método utilizado es el Método de Historia de Vida y tuvo como objetivos analizar las consecuencias del uso abusivo de bebida alcohólica y discutir la asistencia a la salud que es necesaria y cual la asistencia médica que está disponible. Las 30 (treinta) personas declarantes tenían entre 20 y 60 años. El estudio mostró que las mujeres hacen uso abusivo de bebida alcohólica para olvidar o amenizar las consecuencias de las dificultades financieras; divergencias en la relación conyugal; violencia física; exhaustiva jornada de trabajo. Las consecuencias del consumo abusivo son problemas de salud; privaciones; malos tratos; dificultades en la relación familiar y conyugal; problemas físicos; psicológicos; tentativa de suicidio; abandono de los hijos y del marido. Conclusiones: las mujeres no mencionaron ninguna oferta de servicios de salud. Toda y cualquier iniciativa gubernamental tiene que ser incluyente, valorizando y dando incentivo a la participación de la comunidad y de Organizaciones de la Sociedad Civil, congregando acciones y conocimientos de las áreas tecnológicas, humanas y de salud.

Palabras-claves: Enfermería. Mujer. Alcoholismo. 


\section{INTRODUÇ̃̃O}

A presente investigação é um recorte da Tese de Doutorado desenvolvida no Programa de Pós-Graduação em Enfermagem da Escola de Enfermagem Anna Nery/ Universidade Federal do Rio de Janeiro. 0 estudo de natureza qualitativa deu prosseguimento à investigação desenvolvida no Curso de Mestrado que visou à resolutividade na Consulta de Enfermagem no Pré-Natal.

No cotidiano assistencial, deparamo-nos com um fato preocupante: ao longo desses anos, observamos um aumento considerável do número de mulheres que fazem uso de bebida alcoólica, em geral; em particular, enquanto enfermeiras, ao realizarmos a consulta de pré-natal, percebemos o mesmo nas mulheres gestantes, o que representa, entre outros problemas, uma séria ameaça à integridade física do feto.

A problemática originada do uso abusivo de bebidas alcoólicas vem causando preocupação aos governos de vários países. Em países desenvolvidos, como os Estados Unidos e a Comunidade Européia, este já é considerado um problema maior de saúde pública, e os países em desenvolvimento - como é o nosso caso - vêm, da mesma forma, mobilizando os governos no sentido de criarem Programas e Campanhas de Prevenção, devido também a alto índice de acidente, morte e violência geradas pelo consumo abusivo de bebida alcoólica' .

Diante do exposto, definimos como objeto de estudo: 0 uso abusivo de bebida alcoólica por mulheres. Entendemos ser este um problema de enormes proporções, que transcende sua condição de fertilidade, idade, classe social, etnia, etc. Foram elaboradas as seguintes questões norteadoras: Por que a mulher utiliza bebida alcoólica de forma abusiva? Que assistência de saúde procura? A partir do exposto, foram elaborados os seguintes objetivos: Analisar as conseqüências do uso abusivo de bebida alcoólica e discutir a assistência de saúde que precisa e que dispõe.

\section{METODOLOGIA}

Optamos por utilizar o Método de História de Vida, por considerá-lo o mais apropriado para dar voz a essas mulheres. A opção pela abordagem qualitativa se deu em função de esta permitir que o pesquisador obtenha informações que traduzam subjetivamente a essência de toda uma vida de uma pessoa 2 . 0 Método História de Vida consiste na oportunidade dos sujeitos em relatar sua vida, tal e qual sua visão de mundo e de sua realidade. Constitui uma narrativa utilizada pelo sujeito para exprimir os conteúdos de uma parte de sua experiência vivida3.

0 termo História de Vida originou-se do vocábulo francês "histoire" que, ao ser traduzido para o inglês, apresenta-se sob a forma de dois outros vocábulos: story e history, cada um possuindo significados distintos ${ }^{3}$.

Apesar de valorizar o conhecimento das vivências e experiências de cada indivíduo em particular, o Método de História de Vida permite projetarmos esta realidade singular para uma realidade também possível ao grupo social no qual este indivíduo está inserido. "Toda entrevista individual traz à luz direta ou indiretamente uma quantidade de valores, definições e atitudes do grupo ao qual o indivíduo pertence" 4.31.

As entrevistas foram transcritas imediatamente, fato este que propiciou a organização das idéias em relação ao questionamento da entrevista aberta e um ponto de saturação. Recorreu-se à análise temática para compreensão dos significados manifestos e latentes dos depoimentos ${ }^{5-6}$.

Os sujeitos do estudo foram 30 depoentes, das quais quatro, ou seja 13,3\%, eram originárias do ambulatório de um hospital público, onde acompanhavam os filhos em tratamento da síndrome alcoólica fetal (SAF); 14, ou 46,7\% eram provenientes das salas dos Alcoólicos Anônimos (AA), e 12, representando $40 \%$, estavam detidas em um presídio feminino. Vale ressaltar que o Método de História de Vida preconiza a diversificação dos sujeitos da pesquisa.

A faixa etária das depoentes variou dos 20 aos 60 anos. Do total, sete encontravam-se na faixa dos 20 anos, o que corresponde a $7 \%$ do total de participantes. Cinco encontravam-se na faixa dos 30 anos, representando um percentual de 16,6\%. Tanto para a faixa dos 40 quanto dos 50 anos, tivemos a representação de oito mulheres, o que corresponde a um percentual de $26,7 \%$ para cada grupo, respectivamente. Finalmente encontramos duas com 60 anos de idade, constituindo $6,7 \%$.

Para identificação das clientes, preservando o anonimato, optamos por utilizar nomes de minerais, visando ao preconizado na Resolução №. 196/96 do CNS, em relação à preservação do anonimato. As depoentes que concordaram em participar do estudo assinaram Termo de Consentimento Livre e Esclarecido. 0 projeto de pesquisa foi aprovado pelo Comitê de Ética e Pesquisa do Hospital Escola São Francisco de Assis e Escola de Enfermagem Anna Nery.

\section{ANÁLISE E DISCUSSÃO}

0 estudo evidenciou que apenas as depoentes que estavam acompanhando seus filhos portadores de SAF, no tratamento ambulatorial em um hospital público, tiveram acesso a um suporte da equipe de saúde. Normalmente recorrem ao neurologista e à psicóloga, quando necessitam. Em relação ao uso de bebida alcoólica, com exceção da depoente Turmalina Melancia, todas as outras mães de crianças com SAF mantiveram-se abstêmias.

As mulheres que integravam os AA também se mantiveram abstêmias graças à Programação do Grupo, que preconiza a sobriedade a "cada 24 horas". Em seus depoimentos, algumas relataram estar em acompanhamento psicológico, como as depoentes Citrino e Pedra do Sol, por exemplo.

Com as mulheres detentas, o quadro é completamente diferente. Não fizeram nenhum tipo de tratamento para os problemas advindos do uso abusivo do álcool, não tiveram 
consciência de sua dependência, e a abstinência lhes foi imposta pela situação de reclusão.

Das 30 mulheres entrevistadas, cinco, 16,7\%, eram casadas. Três, $10 \%$, eram solteiras, $21,70 \%$, eram separadas, e uma, 3,3\%, viúva, cujo cônjuge veio a falecer em virtude das complicações do alcoolismo.

Os depoimentos, depois de transcritos, foram organizados a partir dos pontos de convergência com o objeto de estudo em questão, permitindo-nos, durante este processo de construção, realizar uma reflexão sociológica, à luz dos aspectos sócioculturais e sócio-simbólicos envolvidos ${ }^{3}$.

A importância de se iniciar a análise temática logo no início da pesquisa de campo deve-se à apreensão dos verdadeiros significados. Sua transformação em objeto sociológico demanda tempo e reflexão apurada e, portanto, deve iniciar o mais precocemente possível $^{3}$.

A desarmonia, seja familiar ou conjugal, surgiu dos depoimentos, como grande "protagonista" destas histórias de vida em particular. Em primeira instância, foi identificada como responsável por carências afetivas muito grandes. Apareceram, em seguida, a pobreza e as jornadas exaustivas de trabalho, como incentivadoras do início do uso de bebidas alcoólicas, ou o posterior consumo abusivo.

As quatro mulheres que estavam acompanhando os filhos portadores de SAF, em tratamento ambulatorial, vêm de origem pobre, vivendo com bastante dificuldade. Todas relataram que a bebida alcoólica, de alguma forma, foi introduzida em suas vidas, na tentativa de esquecer ou amenizar as dificuldades financeiras, as divergências na relação conjugal (inclusive com violência física, como no caso de Turmalina Melancia), ou o cansaço devido à exaustiva jornada de trabalho.

Além das dificuldades materiais, as depoentes Turquesa e Turmalina Melancia também apresentaram problemas de saúde advindos do alcoolismo. Esta última não conseguiu afastar-se da bebida e vive ora em abrigos públicos, ora nas ruas. Recentemente descobriu ser portadora do vírus HIV.

Trabalhava das sete (da manhã) à noite. Virava noite adentro. As vezes meu marido chegava, jantava, ia dormir, eu botava as crianças pra dormir e pegava no ferro pra passar roupa. Lavava de dia e passava de noite. Às vezes duas [...] três horas da manhã eu tava lavando [...] passando roupa, cochilava por cima do ferro[...] aí eu sei que lá vinha aquele roupeiro, no final de semana entregava pra dar... e meu alimento era a bebida [...] eu não tinha nada [...] no meu barraco não tinha nada [...] eu sei que era uma tristeza, e aí tudo isso vai [...] te esgotando, vai te irritando. Aí, você acha que aquela bebida que eu bebia, eu me distraía a minha mente.. (Turquesa)
As 14 depoentes que participam das atividades dos AAs possuem características bem diferenciadas. Dioptásio traz uma história de vida marcada por muitas privações afetivas e materiais, passadas e presentes. Além dela, Kunzita e Citrino também relataram viver atualmente com bastante dificuldade. Não possuem renda própria e dependem de ajuda de amigos e familiares. Nenhuma outra apresenta relato de dificuldade financeira passada ou presente, conseguindo trabalhar, estudar, praticar esportes, etc.

Segundo seus relatos, o primeiro contato com a bebida alcoólica se deu sem dificuldades, durante a adolescência, na própria casa, ou a partir de convívio social, em festas ou "baladas" noturnas. 0 hábito foi se intensificando, transformando-se em dependência rapidamente.

Em seus depoimentos, declararam que a bebida lhes serviu então de "anestésico" para as dificuldades de relacionamento com a família e com o cônjuge.

0 relato de Ágata é bem interessante e exemplifica a questão das relações familiares difíceis:

Aos 11 anos eu perdi minha mãe. Meus pais se separaram aos nove [...] minha mãe era uma pessoa muito forte na minha vida, uma pessoa muito especial [...] muito inteligente e muito amorosa [...] então nossa vida mudou da água pro vinho. Nós tivemos que ir morar com meu pai e uma madrasta horrorosa, megera. Enum lugar horrivel, porque a gente morava num lugar maravilhoso, numa casa no Paraíso, era uma vida maravilhosa, livre. De repente chega e proíbe de ver a avó, mãe de minha mãe. Eu não sei a partir de que momento foi ... não sei se isso é a causa, mas eu sei que dali teve alguma coisa. (Ágata)

Com as mulheres detentas, a realidade não é muito diferente. Algumas relataram experiências similares às mães de crianças com SAF, relatando muitas privações e até maus tratos. Outras, a exemplo das freqüentadoras dos AAs, não referiram problemas de ordem financeira. Vejamos os depoimentos abaixo:

Nunca teve nada dentro de casa. Me lembro como se fosse hoje, acho que minha mãe nunca teve cama. Ela dormia numa esteira [...] no chão. Não lembro de móveis, cama, uma casa arrumada [...] Eu tinha uma irmã Marta que ia pra rua pra pedir pão, porque meu pai sumia e deixava todo mundo com fome. (Calcita Rosa)

Foi maravilhosa (a infância). Nunca faltou nada. Tudo o que eu quisesse meu paime dava. (Turmalina Rosa) 
Com relação aos motivos do consumo abusivo, também para elas, as relações pessoais conturbadas foram apontadas como desencadeantes do uso e abuso de bebidas alcoólicas.

A depoente Heliotrópio, por exemplo, tem um relato marcado por momentos muito difíceis vividos na infância, com relacionamento penoso com a mãe:

\section{Minha infância não foi muito boa não [...] Fui pro colégio interno. Aífiquei lá até os seis anos mais ou menos, até menos que isso. Ela me tirou de lá porque descobriu que tinha infecção renal, aí o médico mandou me tirar de lá, pra fazer o tratamento. Fui morar com ela numa casa de cômodo no Andaraí [...] A minha mãe ia trabalhar e me deixava com meus irmãos, mas menino não quer ficar dentro de casa [...] Aí eu ficava lá... às vezes... Fui abusada lá. Mas não sei se ela não sabia, ou se fingia que não sabia das várias coisas que aconteciam comigo. Acho que na verdade ela não queria ver, né? Nisso eu fui crescendo uma criança meio revoltada [...] comecei a beber pra ficar mais leve.(Heliotrópio)}

No sentido de preservar a conotação de pesquisar, com o intuito de obter subsídios para trazer resolutividade à prática profissional da equipe de saúde - em particular da Enfermagem, assim como colaborar para a melhoria das condições de saúde da população em tela, optou-se por iniciar a "busca" de conhecimento deste "universo" tão singular, no contexto sóciocultural, particularmente enfocando a situação da Saúde da mulher contemporânea, em especial, da mulher brasileira, acreditando ser este um marcador substancial da inserção e importância femininas na sociedade.

Acreditamos que este seja um enfoque significativo, podendo ser considerado um "termômetro" da importância atribuída ao sujeito mulher, dentro do contexto social vigente a cada época, considerando que, junto com a população de crianças, as mulheres somam a maior parcela do contingente populacional existente no Brasil e no mundo.

Pensamos que a situação de saúde destas mulheres influencia e é, ao mesmo tempo, influenciada por sua afinidade com o meio em que vive. Nesta relação, estão envolvidos as qualidades de vida, acesso à educação, alimentação, lazer, entre outros aspectos.

No que concerne à utilização de bebidas alcoólicas, aqui colocada na figura de protagonista de alguns distúrbios da saúde mental da mulher, temos que ela aparece como a quinta causa de internações psiquiátricas, no período de 2000 a 2002. Apesar de ter apresentado um aumento anual de, respectivamente, $3,4 \%, 3,6 \%$ e 3,8\% neste triênio, é englobada nas patologias psiquiátricas, sem aprofundamento de suas origens psicossomáticas, bem como adequação do enfoque da assistência dispensada, considerando-se as particularidades já constatadas e relacionadas ao alcoolismo feminino.
A redução de danos consiste em um conjunto de estratégias de construção de novos "caminhos" para o usuário. Não pretende somente 0 alcance da sobriedade, mas sim um novo "estilo" de tratamento que leva em conta as singularidades do sujeito que apresenta problemas com a bebida, buscando melhor qualidade de vida para ele e para todos os que com ele convivem.

Para ter eficácia:

...a proposta de redução de danos deve ser operada em interações, promovendo o aumento da superfície de contato, criando pontos de referência, viabilizando 0 acesso e 0 acolhimento, adscrevendo a clientela e qualificando a demanda, multiplicando as possibilidades de enfrentamento do problema da dependência no uso do álcool e outras drogas ${ }^{7: 11}$.

Baseia-se na construção de redes de suporte social, que interajam mutuamente, de forma abrangente, utilizando recursos que possibilitem e favoreçam a autonomia dos usuários e familiares que estejam verdadeiramente comprometidos com a defesa da vida. Além do setor saúde, devem comprometer-se também outros, como o de trabalho, promoção social e educação. Todos os recursos destas redes de suporte social devem garantir a continuidade do processo de promoção, prevenção, tratamento e recuperação dos usuários e suas famílias.

A rede de suporte social é formada:

de profissionais, familiares, organizações governamentais e não-governamentais em inteiração constante, cada um com seu núcleo espećíico de ação, mas apoiando-se mutuamente, alimentando-se enquanto rede - que cria acessos variados, acolhe, encaminha, previne, trata, reconstrói existências, cria efetivas alternativas de combate 吕 que, no uso das drogas, destrói a vida $7: 11$

Os problemas relacionados ao uso e abuso de bebidas alcoólicas não podem ser tratados apenas segundo o enfoque de saúde/doença, pois perpassam as esferas da educação, justiça, de desenvolvimento e social, demandando um envolvimento coletivo, para que esta política seja efetivamente colocada em prática.

Com a normatização da Política de Atenção Integral aos Usuários de Álcool e outras Drogas, o Ministério da Saúde definiu que todas as propostas nela contidas devem estar em consonância com os pressupostos que norteiam a Área Técnica de Saúde Mental/Álcool e Drogas - MS, e também vinculadas a outras áreas também do Ministério da Saúde.

Face à gravidade da problemática que envolve o uso abusivo de bebidas alcoólicas, descritas aqui de forma sucinta, sentimos a urgência de abrir um parêntese - fazendo uma pausa nesta 
exposição de cunho teórico, para que possamos expor nossas inquietações.

Consideramos, mais do que importante, imprescindível, trazer à pauta de reflexão o contraponto que observamos entre as propostas contidas nessas políticas; e a realidade que captamos nos depoimentos das mulheres que fizeram parte deste estudo.

Com base no exposto até o momento, e nas informações que apresentamos no decorrer da descrição desta Categoria, percebemos que os serviços idealizados e os existentes para este público-alvo, dispõem, em sua organização funcional, de infra-estrutura para prestar assistência a todo e qualquer indivíduo com problema de uso e abuso de bebidas alcoólicas.

No entanto, não observamos nos depoimentos qualquer referência à procura e/ou oferta destes ou de outros serviços. $A$ exceção diz respeito àquelas que encontraram apoio nos AAs. Não sabemos, portanto, se esta "ausência" se deu pela opção de não procurar o serviço, pela dificuldade de acesso, inserção no serviço (falta de vagas, etc), medo, vergonha ou desconhecimento, por parte dessas mulheres.

0 que podemos afirmar, sem hesitação, é que todas elas necessitavam dos serviços oferecidos por estes programas e políticas. Destacamos aqui, a título de exemplo, dois depoimentos em que se apresentavam alguns dos agravos citados acima:

O meu problema era o álcool, a cachaça, o uísque [...] Eu cheguei a ficar doente durante dois anos por causa disso. [...] Tentei três vezes me suicidar. (Turmalina Rosa).

Bebida era lazer pra mim [...] Todo dia tinha que tomar cerveja, conhaque, alguma coisa. Até que comecei a cair no ridículo. Eu fazia as coisas e depois não lembrava. E as pessoas vinham me falar - as amigas - "Ontem você tava que tava. O que você aprontou mulher? Aquele cara falou que vai te matar" Então aquilo, todo final de semana, vinha um, dois, três que falavam aquilo [...] Quando eu acordava no dia seguinte, ficava com a mente confusa, não lembrava mesmo. (Quartzo Fumê)

Turmalina Rosa revelou em seu relato que, além de problemas físicos, apresentava problemas psicológicos, que a levaram a tentar suicídio, a abandonar os filhos e o marido.

Por sua parte, Quartzo Fumê relatou que começou a beber e usar outras drogas por influência do marido que era traficante de drogas. Tinha uma relação marcada por violência, traições (por parte dele) e muita repressão. Na bebida encontrava a "válvula de escape" para as dificuldades de relacionamento. Com o tempo, o uso abusivo acabou por agravar os problemas conjugais, e trazer-lhe também problemas de relacionamento sociais (causados em função de um comportamento alterado pela ação do álcool. A perda da memória, os "apagamentos" são um exemplo disso), inclusive com ameaça de morte. As duas depoentes encontravam-se presas em regime carcerário. Seus relatos não apresentavam qualquer menção de procura ou oferta de ajuda profissional, quer seja antes ou durante sua prisão. Ao contrário, o que podemos deduzir é que os problemas se agravaram, e talvez tenham contribuído de alguma forma para que se envolvessem com a criminalidade.

Essas são opiniões que, embora tenham sido baseadas nos relatos a nós apresentados, não surgiram a partir de afirmações verbalizadas pelas depoentes. Trata-se de conjecturas que nos remetem a refletir sobre a realidade que se apresenta, de forma mínima, da situação de saúde da população alcoolista.

É mister destacar a importância do atendimento personalizado aos usuários de bebidas alcoólicas e outras drogas. A grande dimensão territorial que possuímos, aliada à pobreza, falta de segurança, educação básica e estrutura econômica, é, indubitavelmente, um fator dificultador. Além de apresentar-se distintamente nas diversas sociedades, também influencia, diferentemente, cada indivíduo em particular.

Por este motivo, entendemos que se faz necessário não perder de vista a necessidade de se considerar esta diversidade. Toda e qualquer iniciativa governamental, quer seja municipal, estadual ou federal, deve ser inclusiva, valorizando e incentivando também a participação da comunidade, de Organizações da Sociedade Civil, congregando ações e saberes das áreas tecnológicas, humanas e da saúde.

Neste sentido, ciente da magnitude e complexidade da questão, a Secretaria Nacional Antidrogas - SENAD, do Gabinete de Segurança Institucional da Presidência da República, resolveu remodelar a política brasileira sobre drogas, vigente desde 2001. Para isso, procurou levar em conta todo 0 processo de modificações ocorrido nesses anos, nos contextos regionais, nacionais e internacionais - considerando mudanças sócio-político-econômico-tecnológicas a que todos, indistintamente, se submeteram.

Acreditamos que a mulher de quem falamos faz parte do contingente populacional que apresenta problemas de ordem física e psíquica que não estão previstos nestes Modelos de Assistência de que se dispõe hoje. Encontra-se desvalida de uma ajuda profissional efetiva, seja pela precariedade da assistência como um todo - realidade de toda a Saúde no Brasil-ou pela falta de pessoal qualificado para assisti-la com resolutividade, no que concerne ao beber de forma abusiva.

Como indivíduo, se por um lado padece pela falta de suporte do Sistema, para Ihe ajudar a lidar com sua doença, por outro, também padece pelo preconceito e discriminação, originados e alimentados pelo desconhecimento e pela desigualdade social.

Esta mulher a quem nos referimos adoece por solidão, insegurança, despreparo, instabilidade emocional, cansaço físico e emocional, sobrecarga de trabalho, obrigações, responsabilidades e outros tantos problemas. Busca na bebida 
alcoólica o alívio, o "anestesiamento" e um êxtase, que, quando consegue alcançar, é momentâneo, deixando, na verdade, um saldo cada vez maior e mais negativo, carregado de discriminação, culpabilização, regado a perdas morais, materiais e afetivas.

Presa nesta verdadeira "teia", não consegue se desvencilhar sozinha do problema. Muitas vezes não tem apoio familiar e, por vergonha e medo, não procura ajuda institucional. Quando o faz, comumente é diagnosticada e tratada de forma equivocada (como portadora de distúrbios psiquiátricos, por exemplo) ${ }^{9}$, sem que o profissional valorize os problemas inerentes ao gênero feminino e considere a possibilidade do alcoolismo como a "ponta do iceberg" de uma questão muito mais profunda.

Na verdade continuamos atreladas à nossa "natureza" maternal, somos força de trabalho ativa e produtiva na sociedade, mas ainda detemos a responsabilidade maior atribuída ao papel de mãe e esposa, absorvendo mais o ônus destas funções (dentro e fora do lar) do que usufruindo as vantagens que elas possam propiciar.

Diante do exposto, atrevemo-nos a afirmar, quando pensamos na problemática específica da mulher alcoolista, que, mesmo que estas políticas estivessem se desenvolvendo "a todo vapor", ainda assim apresentariam lacunas.

0 que se vê e se pode sentir é que o discurso de independência ainda é um pouco ilusório, pois a realidade que se apresenta é diferente. A atual oferta de serviços de saúde hoje disponibilizada é prova clara da representação que se faz da mulher na sociedade moderna, ou seja, continua sendo vista como "matriz" em detrimento das atuais e reais necessidades existentes.

Por este motivo, pensamos ser necessário repensar o Modelo de Assistência à Saúde vigente, em que o profissional esteja capacitado para reconhecer as singularidades próprias da mulher alcoolista, intervindo de forma humanizada, respeitando, compreendendo e descobrindo verdadeiras carências. Para isso, o profissional deve se apropriar de conhecimento necessário, quer seja, aprofundar-se nas questões que envolvem o gênero feminino, dentro da perspectiva do atual contexto socio-econômico e cultural. Só assim, poder-seá dizer que se dispõe de uma assistência integral de saúde a esta mulher.

Em se tratando de Modelos de Assistência centrados nas reais necessidades do indivíduo a quem estas ações se destinam, afirmamos mais uma vez que na Enfermagem podem-se encontrar inúmeras propostas que consideram o sujeito, segundo suas especificidades e contexto próprios.

Utilizando-nos do exemplo das mulheres que participaram deste estudo, podemos afirmar que, numa análise generalizada, são mulheres que viveram suas dificuldades, dores, sofrimento e problemas de saúde quase sempre sozinhas. Pode-se inferir que, provavelmente, esta solidão foi intensificada pelo despreparo da família, amigos, cônjuges e parentes, para lidar com o alcoolismo feminino, uma das fortes marcas da influência das questões de gênero.

0 relato de vida de Calcita Rosa foi, sem dúvida, um dos que mais nos chamou a atenção, por apresentar uma história repleta de dores, sofrimento, indiferença e abandono de pai, marido e familiares. A mãe morreu quando tinha ainda seis anos, devido a problemas com o alcoolismo. As lembranças dessa época foram marcadas pela fome, miséria e muitas agressões físicas e morais, feitas pelo pai, direcionadas à sua mãe, irmãos e a si mesma. Ele também bebia muito e pouco aparecia. Quando isso acontecia, era agressivo e batia muito em todos.

Após a morte da mãe, as irmãs mais velhas assumiram os cuidados com os mais novos, mas, devido à violência do pai, acabaram indo embora. Cresceu praticamente sozinha, com ajuda esporádica de vizinhos. Não tinha parentes no Rio de Janeiro. Passava fome e todo tipo de privações. 0 alcoolismo permeou toda esta trajetória. Começou a beber com 14 anos e só parou quando foi presa. Teve quatro filhos de parceiros diferentes, também com relacionamentos marcados pela pobreza, violência, abandono. Com um deles se envolveu no narcotráfico, motivo pelo qual acabou presa. Dois de seus filhos se envolveram na marginalidade. Um foi assassinado, e o outro também está preso. 0 mais novo vive ora na casa de uma vizinha, ora com uma comadre ou com o irmão de 19 anos. Não recebe quase a visita dos filhos. As notícias chegam por carta, da comadre ou do filho de 19 anos.

Em nenhum momento relatou algum acontecimento feliz, alguma boa lembrança. Só dores e tristezas. Neste cenário, a bebida alcoólica atuou como atenuante das dores e "válvula de escape" para o sofrimento.

Assim como no caso desta depoente, a situação de solidão e afastamento de familiares também era comum na maioria dos relatos de vida. Do total das 30 depoentes que participaram da pesquisa, 21 estavam separadas. Das quatro que acompanhavam o tratamento dos filhos com SAF, apenas Amazonita continuava vivendo com o parceiro e os filhos, tendo conseguido contornar as crises conjugais, ocorridas no período em que era dependente de bebida alcoólica. As depoentes Ametista e Turquesa viviam sozinhas, responsáveis pelos filhos, que ainda eram pequenos. Turmalina Melancia também vivia sozinha nas ruas, ou em abrigos do governo. Depois que se descobriu portadora do vírus HIV, declarou ter receio de manter relações sexuais.

As participantes dos AAs, como dito antes, eram heterogêneas em suas realidades de vida. Apenas quatro das 14 depoentes eram casadas ou viviam com companheiro e os filhos. Duas eram solteiras, e as demais estavam separadas. Neste cenário foram comuns os relatos de afastamento dos filhos, cônjuges, amigos e familiares, por conta do alcoolismo delas.

Em relação às mulheres que se encontravam em regime de detenção, todas estavam separadas. A maioria havia perdido o contato com os filhos e recebia poucas visitas de familiares ou amigos. 
0 isolamento, seja ocasionado por iniciativa própria ou pela família, é comum na vida do alcoolista. No caso da mulher, o é ainda mais, pois, via de regra, não se aceita e/ou compreende que ela "deixe de lado" suas "obrigações" enquanto mãe, esposa e dona de casa, perdendo o controle de sua vida para a bebida alcoólica.

Aliando a literatura com o conhecimento que apreendemos no contato com as histórias de vida destas mulheres, percebemos que, sem o apoio da família, a recuperação e a sobriedade tornam-se muito mais difíceis e, sem dúvida, muito mais dolorosas; além de dificultar a atuação profissional envolvida no processo de prevenção, promoção e tratamento do problema.

Pensamos então que a família pode ser considerada um dos pilares dos procedimentos voltados à "reconstrução" de vida dessas pessoas. Dessa forma, deve ser incluída no decurso do cuidar, sendo ela também alvo de cuidados e orientações.

No que diz respeito à Enfermagem, o cuidado com a família já é alvo de interesse, não só pelos aspectos aqui abordados, mas pelo reconhecimento de sua importância na estrutura social, como um todo.

0 meio familiar pode ser considerado provedor de saúde de seus componentes, cuidando e amparando na doença, agindo como parceira da equipe de saúde ${ }^{8}$.

Reconhecendo a importância da família, enquanto eixo de equilíbrio do ser humano, principalmente nas situações envolventes e envolvidas na problemática do uso e abuso de bebidas alcoólicas, concordamos que é imprescindível para o profissional que trabalha com a clientela alcoolista a inclusão da família na realização das ações e intervenções necessárias, instrumentalizando-a com as orientações e esclarecimentos específicos e inerentes à problemática em tela.

Para isso, contudo, faz-se necessário que o profissional conheça a dinâmica de funcionamento e articulação desta família e seus membros.

A Enfermagem, ao comprometer-se com a família como unidade a ser cuidada, focaliza sua atenção nas interações intra e extrafamiliares, busca conhecer o processo de viver da família, as transições e crises que enfrentam, identificando suas fragilidades, fontes de estresse, recursos e seus modos de cuidar. Entre as ações terapêuticas que a Enfermagem desenvolve com a família, foram identificadas: reconhecimento da família como sujeito do seu processo de viver e se cuidar, com direitos e responsabilidades; o ouvir atentamente; ser sensível, estar presente, comprometer-se, lutar, respeitar e garantir os direitos da família; incentivar o cuidado familial; trabalhar em sintonia com outros profissionais e buscar o aperfeiçoamento pessoal e profissional, entre outros ${ }^{10: 94}$.

A problemática do uso abusivo de bebidas alcoólicas é complexa e se agrava muito mais quando é a mulher quem bebe. Sendo assim, a enfermeira, enquanto membro da equipe de saúde, deve lançar mão de todos os recursos possíveis e disponíveis. Deve estar atenta às queixas e sintomas relatados, não desconsiderando nenhum dado que possa auxiliar no diagnóstico da situação. Também deve valorizar e respeitar crenças, costumes e limitações, considerando-os na formulação e implementação das ações e cuidados direcionados à clientela.

A mulher que consome abusivamente bebida alcoólica necessita, sobretudo, de apoio e compreensão, para que se sinta à vontade para expor seus sentimentos e pensamentos. $\mathrm{A}$ partir de uma relação interativa com a cliente, a enfermeira poderá ajustar não só suas ações e procedimentos para com a cliente em particular, como também instrumentalizar a família para que ofereça o suporte necessário.

Orientar para hábitos de vida mais saudáveis, utilizando ações e práticas educativas, bem como controlar sua saúde física e mental, corresponde a algumas das possíveis abordagens que certamente contribuirão para o alcance da resolutividade na assistência prestada.

Tomando como base os depoimentos destas mulheres, percebemos que a mesma sociedade que não aceita e julga com severidade as mulheres que apresentam problemas oriundos do beber excessivamente, pressionando-as para que parem de beber, por outro lado, imprime pouca ou nenhuma pressão para que comecem a beber ${ }^{9}$. Acrescenta-se que os fatores culturais e sociais: “....inda exercem poderosa influência sobre o padrão de beber e sobre a quantidade ingerida pelas mulheres, alterando sua vulnerabilidade para o desenvolvimento de problemas com álcool ${ }^{11:-153}$ ".

Sendo assim, julgamos necessário aprofundar as reflexões acerca da influência da cultura no hábito de beber, abordando a questão do uso/abuso de bebidas alcoólicas por mulheres.

\section{CONSIDERAÇÕES FINAIS}

0 estudo evidenciou perdas, materiais, sociais, familiares e, até mesmo pessoais. As perdas materiais, físicas e/ou emocionais se refletem no individual e no coletivo. Confirmamos, através destas mulheres, que o alcoolismo é uma doença que afeta o "entorno" daquele que bebe.

Os relatos apresentados descortinam uma realidade "paralela". 0 mundo da mulher alcoólica certamente é menos "colorido", menos interessante e desafiador. Por não conseguir conviver com esta realidade, ela busca na bebida alcoólica as cores e as formas que deseja, na ilusão de suprir o "vazio" que sente em sua existência.

Acreditamos que serão necessárias uma reordenação e remodelação do modo de assistir à mulher que apresenta problemas com a bebida alcoólica; iniciando pela atenção para o diagnóstico.

Precisamos, de uma vez por todas, deixar de lado esta prática que ainda se norteia pelo modelo cartesiano (biomédico) de cuidar. Precisamos adotar uma prática voltada à concepção holística do cuidar; considerando o indivíduo enquanto mente, 
corpo e espírito. Não há aqui conotação religiosa, mas compreensiva do Ser, em toda a sua plenitude.

Entendemos que a Enfermagem possui um papel altamente relevante no cuidado à mulher alcoolista, quer seja nas orientações voltadas à prevenção, ou nas ações direcionadas à promoção da saúde e recuperação.

As Atividades de Educação em Saúde, voltadas à prevenção, devem considerar todos os aspectos pertinentes à questão, orientando, esclarecendo (a todos, sem exceção, tendo ou não problemas com o uso abusivo de bebidas alcoólicas) quanto aos comprometimentos físicos (doenças dos diversos aparelhos do corpo humano, incluindo as doenças sexualmente transmissíveis), psíquicos (transtornos de memória, etc), sociais

\section{Referências}

1- Atkinson R. The life story interview. Thousand Oaks (USA): Sage Publications; 1998.

2- Lima JMB. Alcoologia: uma visão sistêmica dos problemas relacionados ao uso, abuso do álcool. Rio de Janeiro(RJ): EEAN/UFRJ; 2003.

3- Bertaux D. L'approche biographique: sa validité méthodologique, ses potentialités in histoires de vie et vie sociale. Cah Int Sociol 1980; 27(69): 197-225.

4- Glat R. Somos iguais a vocês; depoimentos de mulheres com deficiência mental. Rio de Janeiro (RJ): Agir; 1989.

5- Dias IMAV, Santos RS. Os profissionais de enfermagem diante do nascimento da criança com malformação congênita. Esc Anna Nery Rev mar; $11(1): 73-9$.

6- Nascimento FA, Almeida MC, Souza JG, Lima JMB, Santos RS. A enfermeira pediatra cuidando de crianças/adolescentes com Síndrome (violência, acidentes, etc) e familiares (desestruturação, violência, entre outros).

Em quase todos os casos, a família do alcoolista precisa de ajuda tanto quanto ele, pois que normalmente se encontra desestruturada e despreparada para lidar com a problemática em questão. Apoio, orientações e esclarecimentos acerca da doença, sua evolução e características, bem como encaminhamento a outros profissionais da equipe interdisciplinar (psicólogos, médicos, assistentes sociais, entre outros) são ações resolutivas.

0 conhecimento das causas certamente auxilia, mas não resolve inteiramente, pois representa tão somente parte do problema; um "pedaço" da história de vida de cada pessoa, em particular.

Alcoólica Fetal - SAF. Esc Anna Nery Rev Enferm 2007 dez; 11(4): 619-24.

7- Ministério da Saúde (BR). A política do Ministério da Saúde para atenção integral a usuários de álcool e outras drogas. $2^{\mathrm{a}}$ ed. Brasília (DF); 2004.

8Política Nacional sobre Drogas. Brasília (DF); 2005.

9- Elsen I, Althoff CR, Manfrini GC. Saúde da família: desafios teóricos. Fam Saude Desenvol 2001 jul; 3(2): 89-97.

10- Mattos CM, Althoff CR, Elsen I, Patrício ZM, organizadores. Marcos para a prática de enfermagem com famílias. Florianópolis (SC): UFSC; 1994.

11- Edwards G, Marshall EJ, Cook CCH. 0 tratamento do alcoolismo. um guia para profissionais da saúde. $4^{\mathrm{a}}$ ed. Porto Alegre (RS): Artmed; 2005. 